\title{
The nonparasitic phase of Dermacentor nitens under field conditions in southeastern Brazil
}

\author{
A fase não-parasitária de Dermacentor nitens em condições de campo no \\ Sudeste do Brasil \\ Marcelo Bahia Labruna1* (D); João Luiz Horácio Faccini² \\ Departamento de Medicina Veterinária Preventiva e Saúde Animal, Faculdade de Medicina Veterinária e Zootecnia, Universidade de \\ São Paulo - USP, São Paulo, SP, Brasil \\ 2 Departamento de Parasitologia Animal, Instituto de Veterinária, Universidade Federal Rural do Rio de Janeiro - UFRRJ, Seropédica, RJ, \\ Brasil
}

How to cite: Labruna MA, Faccini JLH. The nonparasitic phase of Dermacentor nitens under field conditions in southeastern Brazil. Braz J Vet Parasitol 2020; 29(4): e008620. https://doi.org/10.1590/S1984-29612020090

\begin{abstract}
Dermacentor nitens is a one-host tick that uses domestic equids as main hosts. Herein, the nonparasitic phase of D. nitens was evaluated under field conditions in Pirassununga, São Paulo state, Southeastern Brazil. By exposing engorged females of $D$. nitens to field conditions (grass plots) for 24 consecutive months, this tick species was able to complete its nonparasitic phase by producing host-seeking larvae in the pasture throughout the year. Preoviposition and egg incubation periods were longer during autumn and winter months than during the other months. The number of larvae generated by engorged females was in most of the times lower during autumn and winter months, as demonstrated by lower egg hatching values. Such conditions could be linked to lower mean temperatures and rainfall. Larvae with the longest longevity hatched from the eggs with the shortest incubation periods. An apparent synchronism of larval hatching during spring was observed from the eggs laid by females during late winter and autumn, which is consistent with the phenomenon of "spring rise". The results indicate that $D$. nitens can complete up to five generations per year in southeastern Brazil, providing baseline data to develop future protocols for the appropriate control of $D$. nitens on horses.
\end{abstract}

Keywords: Tropical horse tick, Ixodidae, seasonal dynamics, spring rise, Brazil.

\begin{abstract}
Resumo
Dermacentor nitens é um carrapato de um hospedeiro, que utiliza equídeos domésticos como principais hospedeiros. Neste estudo, a fase não parasitária de $D$. nitens foi avaliada em condições de campo, em Pirassununga, estado de São Paulo, no Sudeste do Brasil. Fêmeas ingurgitadas de $D$. nitens foram expostas a condições de campo (canteiros de capim) por 24 meses consecutivos. Este carrapato foi capaz de completar sua fase não parasitária, através da produção de larvas infestantes, durante todos os meses do ano. No outono e inverno, os períodos de pré-oviposição e incubação de ovos foram mais longos. O número de larvas geradas por fêmeas ingurgitadas foi menor no outono e inverno, como demonstrado pelos menores valores de eclosão dos ovos. Tal condição poderia estar ligada a temperaturas médias e índices pluviométricos mais baixos. Larvas com maior longevidade nasceram de ovos com períodos de incubação mais curtos. Observou-se um aparente sincronismo da eclosão das larvas durante a primavera, a partir de ovos postos pelas fêmeas durante o final do inverno e outono, consistente com o fenômeno do "pico da primavera". Os resultados indicam que $D$. nitens pode completar até cinco gerações por ano no Sudeste do Brasil, fornecendo bases para futuros protocolos de controle racional de carrapatos.
\end{abstract}

Palavras-chave: Carrapato-da-orelha-do-cavalo, Ixodidae, dinâmica sazonal, pico da primavera, Brasil. 


\section{Introduction}

The genus Dermacentor (Acari: Ixodidae), currently containing 42 tick species, is distributed on all continents except Oceania and Antarctica (Guglielmone et al., 2015). Based on an integrated biogeographical and phylogenetic approach, Lado \& Klompen (2019) strongly supported the hypothesis of an Afrotropical origin for Dermacentor, with later dispersal to Eurasia and the Nearctic and with the genus reaching the New World through the Beringia land bridge, from Southeast Asia. Next, the only two one-host tick species of the genus, Dermacentor albipictus (Packard, 1869) and Dermacentor nitens, Neumann, 1897, evolved in the New World (Lado \& Klompen, 2019). In this scenario, early $D$. nitens populations were probably sustained by native vertebrate species in the Neotropics, where there have been numerous occasional records of $D$. nitens on native mammals (Nava et al., 2017). However, not a single population of this tick species is known to have been sustained by a wild host; i.e., whenever it has been possible to determine, $D$. nitens populations have been sustained only by domestic equids. This tick became widely distributed across South America during the $20^{\text {th }}$ century through the movements of domestic equids (horses and donkeys), currently the most important hosts for D. nitens (Aragão \& Fonseca, 1953; Nava et al., 2017). In addition, to the authors' knowledge, this tick has never been reported from a site without the presence of equids.

Dermacentor nitens has been reported as one of the most common tick species infesting horses in all major Brazilian biomes, i.e., Amazon (Labruna et al., 2005), Atlantic forest (Falce et al., 1983; Labruna et al., 2001; Peckle et al., 2013), Cerrado (savannah) (Labruna et al., 2001; Szabó et al., 2018), Pantanal (wetlands) (Campos et al., 2019), and semiarid Caatinga (Souza et al., 2019). Within these regions, D. nitens has great veterinary importance as it is a vector of Babesia caballi, the agent of equine babesiosis (Kerber et al., 2009) and as high tick burdens can induce anemia (Labruna et al., 2002) and even death (Souza \& Serra-Freire, 1992). In addition, because of the predilection of $D$. nitens to feed inside ears, infestations at this site predispose equids to screwworm infestations (Cochliomyia hominivorax), which commonly lead to permanent damage to ear cartilage (Souza \& Serra-Freire, 1992; Borges et al., 2000; Labruna et al., 2002).

Studies of the nonparasitic phase of ticks under natural conditions are essential to understanding the seasonal dynamics of tick infestations and to providing ecological information for designing appropriate methods of tick control. There has been only one such study for $D$. nitens, in which observations of engorged females, eggs and hatched larvae were performed exclusively inside stainless wire-gauze cylindrical tubes that were left beneath vegetation in a pasture of an area of Minas Gerais state, Southeastern Brazil (Borges et al., 1999). While the observation of ticks confined to cylindrical tubes provides more precise information of the time of oviposition and egg incubation periods, such a methodology has bias toward larval natural behavior (i.e., host seeking or behavioral diapause) that cannot be adequately determined (Labruna et al., 2003).

The present study aimed to evaluate the nonparasitic phase of $D$. nitens under field conditions in one area of São Paulo state, southeastern Brazil, where $D$. nitens was the most common tick species on horses (Labruna et al., 2001). In addition to observing ticks inside cylindrical tubes, ticks were also observed freely in the pasture to gather more realistic data on larval behavior and survival.

\section{Materials and Methods}

\section{Study site}

This study was conducted during 1999-2001 at the experimental farm of the University of São Paulo, Pirassununga

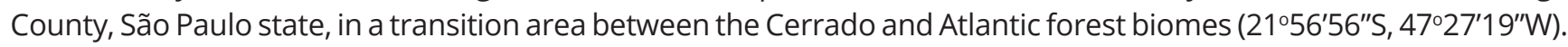
The local weather was characterized by a hot and rainy spring and summer (late September to March) and a cool and dry autumn and winter (late March to September); the mean annual rainfall was typically $\approx 1,300 \mathrm{~mm}$ (Labruna et al., 2002). The present field study overlapped with a complementary study on seasonal dynamics of D. nitens infestations on horses at the same farm, which was performed from October 1997 to September 1999 (Labruna et al., 2002).

A tick-free, animal-proof, 2-ha pasture composed of the grass Brachiaria decumbens was divided into 92 1- $\mathrm{m}^{2}$ plots, which were 1-2 m apart (divided by vegetation-free paths). The grass in the plot was left at $\approx 30 \mathrm{~cm}$ high on the day of tick release (described below), and no grass was removed until the end of the observation period in each plot (Sutherst et al., 1978; Labruna et al., 2003). 


\section{Obtaining ticks}

Engorged females of $D$. nitens were collected from naturally infested horses on the same farm and used to establish a laboratory colony. Free-living stages of the tick colony (preoviposition, oviposition, egg incubation, and unfed larvae) were held in an incubator at $26 \pm 2^{\circ} \mathrm{C}$ and $85 \pm 5 \%$ relative humidity (RH). For the production of engorged females throughout the study, one or two adult horses were infested with $\approx 7,000$ to 10,000 larvae of $D$. nitens at 14-day intervals. Horses were kept in a grass paddock; however, one day prior to the collection of engorged females, infested horses were taken out from the field and held through the night in special stalls adapted to recover naturally detached engorged ticks (Sutherst et al., 1978). Briefly, the stall had an elevated, slatted floor, and engorged females were conveniently collected by flushing them carefully from beneath the elevated, slatted floor (Labruna \& Amaku, 2006; de Barros et al., 2017). The next morning, detached engorged females were collected and selected for this study. For this purpose, engorged females were individually weighed on an electronic balance, and individuals weighing at least $150 \mathrm{mg}$ were selected based on the weight criterion previously adopted by Borges et al. (1999).

The protocols with horses in this study were not submitted to any Ethical Committee on Animal Research because there was no such committee in the author's institutions at the time of the present study (1999-2001), and also because the official Regulation of Animal Research in Brazil (Federal Law number 11794) was published only in 2008. However, during the study all infested horses were constantly evaluated by veterinarians in order to certify their health status.

\section{Experimental groups of ticks}

From March 1999 to February 2001, engorged females were exposed to field experimental conditions at 14-day intervals. At each time point (every 14 days), 45 engorged females collected in the stalls were selected to be exposed to experimental conditions, while the remaining engorged females were used to maintain the tick colony. The 45 selected females were divided into four groups of 10 engorged females and a control group of 5 females and exposed to experimental conditions the same day. Three of the groups of 10 females were left freely on the soil surface under the grass in the middle of three plots (one group of 10 females per plot). The 10 females of the fourth group were individually held inside stainless wire-gauze cylindrical tubes $\left(60 \mathrm{mesh} / \mathrm{cm}^{2}, 61 \mathrm{~mm}\right.$ long, $17 \mathrm{~mm}$ diameter), which were closed with rubber corks and placed horizontally on the soil surface under the grass of a fourth plot. The five engorged females comprising the control group were also placed inside cylindrical tubes, but they were left in an incubator at $26 \pm 2{ }^{\circ} \mathrm{C}$ and $85 \pm 5 \% \mathrm{RH}$ and full darkness.

Plots were inspected weekly, always on Wednesday mornings between 07:00 and 10:00 a.m. Females within the tubes were inspected using a $4 \mathrm{x}$ hand lens to determine the preoviposition period (period between female release and onset of oviposition), egg mass incubation period (period between onset of oviposition and onset of larval hatching), and maximal larval survival period (all measured in weeks). When a female was dead (motionless and shrunken cuticle), it was removed from the tube and weighed. For each dead female, the \% weight lost after oviposition was calculated by using the formula:

$\%$ weight lost $=100-($ female weight after oviposition / engorged female weight $\times 100)$.

Maximal larval survival was defined as the period of time from initial hatching to the last week when at least one live larva was observed in the tube. When all larvae had died, the tube contents were discarded on a plate, and the percentage of hatched eggs (\% egg hatching) was visually estimated under a stereoscope microscope (Labruna et al., 2003). The same procedures were performed with the control females in the incubator.

Plots with free females were inspected weekly by searching for host-seeking larvae on the tips of grasses (questing behavior). The period that elapsed from releasing engorged females in the plot to the first appearance of larvae on the tip of grasses was considered the prehatch period, as previously determined (Harley, 1966). Once larval clusters were observed on vegetation tips, the subsequent weeks in which less than 10 live larvae were present were recorded, and thereafter, the observations of at least one live larva still present on the plot were recorded. When larvae could no longer be found by visual inspection of the plot, the grass was swept up to six times with a wooden bat $(60 \times 7 \times 2.5 \mathrm{~cm})$ covered with white flannelette. If one or more larvae were picked up, then they were manually returned to the grass, which was considered to 
still harbor live larva. Weekly inspections continued until six sweeps per inspection day failed to pick up any larvae for 3 consecutive weeks, and no larvae could be seen on the vegetation (Harley, 1966; Labruna et al., 2003). Larval survival in each plot was determined as the period when the majority of the larvae survived (until less than 10 live larvae were present in the plot) and as the period of maximal survival (until no live larvae were present on the vegetation).

When no live ticks were observed in a plot anymore, it was prepared as detailed above to receive new cohorts of engorged females. Therefore, during the two-year study period, some plots were used more than once. This condition occurred because we had a total of $921-\mathrm{m}^{2}$ plots to receive a total of 208 tick groups throughout the two-year study period, in which four new groups of engorged females were released in four plots every 14 days.

\section{Environmental data}

Maximum and minimum soil temperatures were reported weekly with two digital thermometers (Oregon Scientific, Portland, OR, USA) by placing the sensor probe on the soil base under the vegetation of a plot. Temperature data are presented as the mean of the previous 7 days of each plot inspection. Total rainfall data for the study period were obtained from the meteorological station of the experimental farm, situated $\approx 150 \mathrm{~m}$ from the tick plots. Rainfall data are presented as the sum (in millimeters) of the previous 7 days to each plot inspection.

\section{Statistical analysis}

Under each of the three experimental conditions (control ticks in the incubator, ticks confined to cylindrical tubes in grass plots, and ticks released freely in grass plots), the different tick biological variables were compared between the 12 months of the year, in which engorged females were released under the experimental condition. For this purpose and to enhance robustness of data, all tick groups for the same experimental condition of the same month were pooled; i.e., since tick groups were formed every 14 days during a 24-month period, each month had 4 to 5 tick groups, considering that each month was sampled over two consecutive years. The analyzed tick biological variables were preoviposition period, egg incubation period, $\%$ hatched eggs, female $\%$ weight lost after oviposition, and maximal larval survival period for ticks confined to cylindrical tubes; and prehatch period and survival of unfed larvae (majority or maximal) for ticks released freely in grass plots. The differences between months were assessed by one-way ANOVA with Tukey's post hoc procedure. A variable was considered significantly different between months when $P<0.05$. All analyses were performed using the program Minitab® Release 18 .

\section{Results}

\section{Control ticks in the incubator}

On each day that engorged females were exposed to field conditions, counterpart engorged females comprising the control group were exposed to optimal conditions in the laboratory, i.e., incubator at $26 \pm 2{ }^{\circ} \mathrm{C}, 85 \pm 5 \% \mathrm{RH}$, and full darkness. The only time point when the control group of females could not be formed was in the first fortnight of June 1999, due to the low number of engorged females recovered from horses. All females of the control group oviposited fertile eggs. Their engorged weights before oviposition varied from 150 to $550 \mathrm{mg}$ (mean: $343 \mathrm{mg}$ ). As illustrated in Figure 1, the duration of preoviposition and egg incubation periods were very similar throughout the study period. Some visible notable differences between months could be observed only for maximal larval survival periods, although in all cases larvae hatched and survived for some weeks.

When the results of the two years of observation were pooled together by month, the control group females needed only 1 week to start oviposition, the mean egg incubation period varied from 3.2 to 4.3 weeks, and the mean larval maximal survival period varied from 5.8 to 10.0 weeks (Table 1). Female oviposition success was reflected by the female percentage of weight lost after oviposition in relation to the initial engorged weight, which had mean values varying from 71.9 to $86.3 \%$ for females left in the incubator. Most of the eggs yielded larvae, with a mean percentage of hatched eggs always $>85 \%$. Generally, there were very few significant differences among the biological variables for the ticks of the control group over the 12 months under controlled conditions in the laboratory (Table 1). 


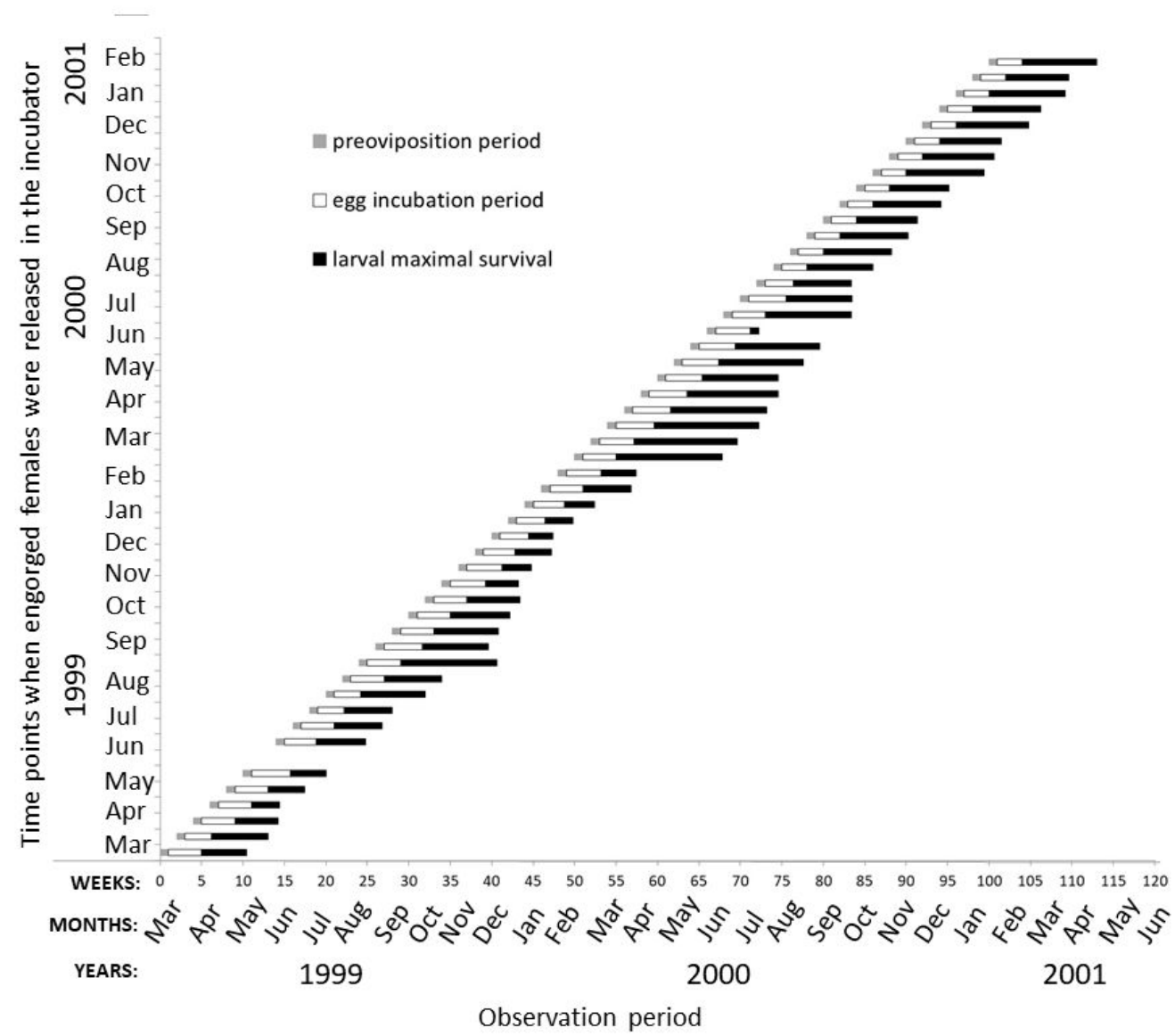

Figure 1. Dermacentor nitens reproductive and survival mean periods for females and larvae, respectively, observed in an incubator at $27^{\circ} \mathrm{C}$ and $85 \pm 5 \% \mathrm{RH}$ during the present study. Groups of engorged females, confined to cylindrical tubes, were placed inside the incubator at 14-day intervals from March 1999 to February 2001.

Table 1. Biological data of Dermacentor nitens engorged females confined to cylindrical tubes in an incubator in the laboratory*.

\begin{tabular}{|c|c|c|c|c|c|}
\hline Months" & $\begin{array}{l}\text { Preoviposition } \\
\text { period (weeks) }\end{array}$ & $\begin{array}{l}\text { Egg mass incubation } \\
\text { period (weeks) }\end{array}$ & \% Egg hatching ${ }^{+}$ & $\begin{array}{c}\text { Female } \% \\
\text { weight lost after } \\
\text { oviposition }{ }^{+}\end{array}$ & $\begin{array}{c}\text { Maximal larval } \\
\text { survival (weeks) }\end{array}$ \\
\hline March & $1.0 \pm 0.0(1-1)$ & $4.0 \pm 0.1(3-5) a, b, c$ & $91.9 \pm 3.1(50-99) a$ & $77.0 \pm 1.9(54-89) a, b$ & $10.0 \pm 0.7(5-14) a$ \\
\hline April & $1.0 \pm 0.0(1-1)$ & $4.3 \pm 0.1(4-5) a$ & $92.5 \pm 3.5(40-99) a$ & $78.3 \pm 2.0(61-90) a, b$ & $7.8 \pm 0.9(3-14) a, b, c$ \\
\hline May & $1.0 \pm 0.0(1-1)$ & $4.3 \pm 0.1(4-5) a$ & $98.3 \pm 0.5(90-99) a$ & $77.8 \pm 2.5(51-97) a, b$ & $7.3 \pm 0.7(3-11) a, b, c$ \\
\hline June & $1.0 \pm 0.0(1-1)$ & $4.1 \pm 0.1(3-5) a, b$ & $96.8 \pm 1.9(70-99) a$ & $80.0 \pm 2.1(68-90) a, b$ & $7.9 \pm 0.6(5-12) a, b, c$ \\
\hline July & $1.0 \pm 0.0(1-1)$ & $3.8 \pm 0.1(3-5) a, b, c, d$ & $88.2 \pm 5.7(15-99) a$ & $86.3 \pm 1.1(76-92) a$ & $7.4 \pm 0.6(5-11) a, b, c$ \\
\hline August & $1.0 \pm 0.0(1-1)$ & $3.4 \pm 0.1(3-4) d, e$ & $99.0 \pm 0.0(99-99) a$ & $83.1 \pm 1.6(63-96) a$ & $7.5 \pm 0.3(4-9) a, b, c$ \\
\hline September & $1.0 \pm 0.0(1-1)$ & $3.8 \pm 0.1(3-5) a, b, c, d$ & $94.3 \pm 2.7(40-99) a$ & $81.4 \pm 2.5(37-95) a, b$ & $8.7 \pm 0.4(5-14) a, b$ \\
\hline October & $1.0 \pm 0.0(1-1)$ & $3.5 \pm 0.1(3-4) c, d, e$ & $95.9 \pm 2.9(40-99) a$ & $82.9 \pm 1.4(66-93) a$ & $7.3 \pm 0.2(6-9) b, c$ \\
\hline November & $1.0 \pm 0.0(1-1)$ & $3.6 \pm 0.1(3-5) b, c, d, e$ & $97.3 \pm 1.3(75-99) a$ & $83.4 \pm 1.2(72-93) a$ & $6.4 \pm 0.6(2-11) b, c$ \\
\hline December & $1.0 \pm 0.0(1-1)$ & $3.3 \pm 0.1(3-4) d, e$ & $87.9 \pm 3.5(55-99) a$ & $72.7 \pm 2.8(41-89) b$ & $5.8 \pm 0.6(2-9) c$ \\
\hline January & $1.0 \pm 0.0(1-1)$ & $3.2 \pm 0.1(3-4) \mathrm{e}$ & $94.2 \pm 2.5(50-99) a$ & $77.3 \pm 2.5(54-93) a, b$ & $6.3 \pm 0.6(3-12) b, c$ \\
\hline February & $1.0 \pm 0.0(1-1)$ & $3.7 \pm 0.1(3-5) a, b, c, e$ & $94.4 \pm 2.6(60-99) a$ & $71.9 \pm 2.3(59-89) b$ & $6.3 \pm 0.6(3-11) b, c$ \\
\hline
\end{tabular}

* The lots of engorged females were formed every 14 days from March 1999 to February 2001; data were pooled for all lots from the same month over the 24-month period; \# refers to the month when the engorged females were released in the incubator; ${ }^{+}$Values presented as the mean \pm standard error (range in parenthesis); different letters in the same column indicate significantly different mean values $(P<0.05)$. Some of the differences could be associated to slight temperature fluctuations due to technical problems related to temperature calibration of the incubator during the study. 


\section{Ticks confined to cylindrical tubes in grass plots}

Ticks confined to cylindrical tubes in grass plots were formed every 14 days, except for mid-July 2000, when the number of engorged females recovered from horses was not enough to form the groups. During the entire study under field conditions, all females confined to cylindrical tubes oviposited fertile eggs that resulted in hatched larvae. The engorged weights of these females varied from 160 to $560 \mathrm{mg}$ (mean: $373 \mathrm{mg}$ ). As illustrated in Figure 2, the duration of preoviposition and egg incubation periods were longer in the autumn (late March to June) and winter (late June to September) months and shorter in the spring (late September to December) and summer (late December to March) months. During the spring of both 1999 and 2000, there was a synchronism in the larval hatching in some plots, specifically those where engorged females were released in the previous winter and late autumn. This spring synchronism coincided with an increase in both temperature and rainfall in the plots after the autumn and winter with lower temperatures and rainfall (Figure 3). While there was larval hatching during all months of the year, the percentage of egg hatching were in most of the times lower for females released immediately prior to the coldest months of the study period (Figure 3), which were the autumn and winter of 1999 and 2000. In addition, the only time that the female percentage of weight lost after oviposition had a drastic reduction was June 1999 (Figure 3).

Comparisons of the pooled data per month for the biological variables showed some marked differences among the 12 months of the year (Table 2). Both preoviposition and egg incubation periods were in most of the times significantly longer for females that were released in the field during the autumn and winter months (between late March and late September) when compared to females released during the spring and summer months (between late September and late March). In addition, the percentage of hatched eggs was also significantly lower for the females that were released in the grass plots from April to July (autumn to mid-winter) than those released in other months. The female percentage of weight lost after oviposition was generally similar throughout the months, although this variable was significantly lower in June (because of the drastic reduction in June 2009, as shown in Figure 3 ) than in most of the other months. Maximal larval survival was significantly longer in plots where females

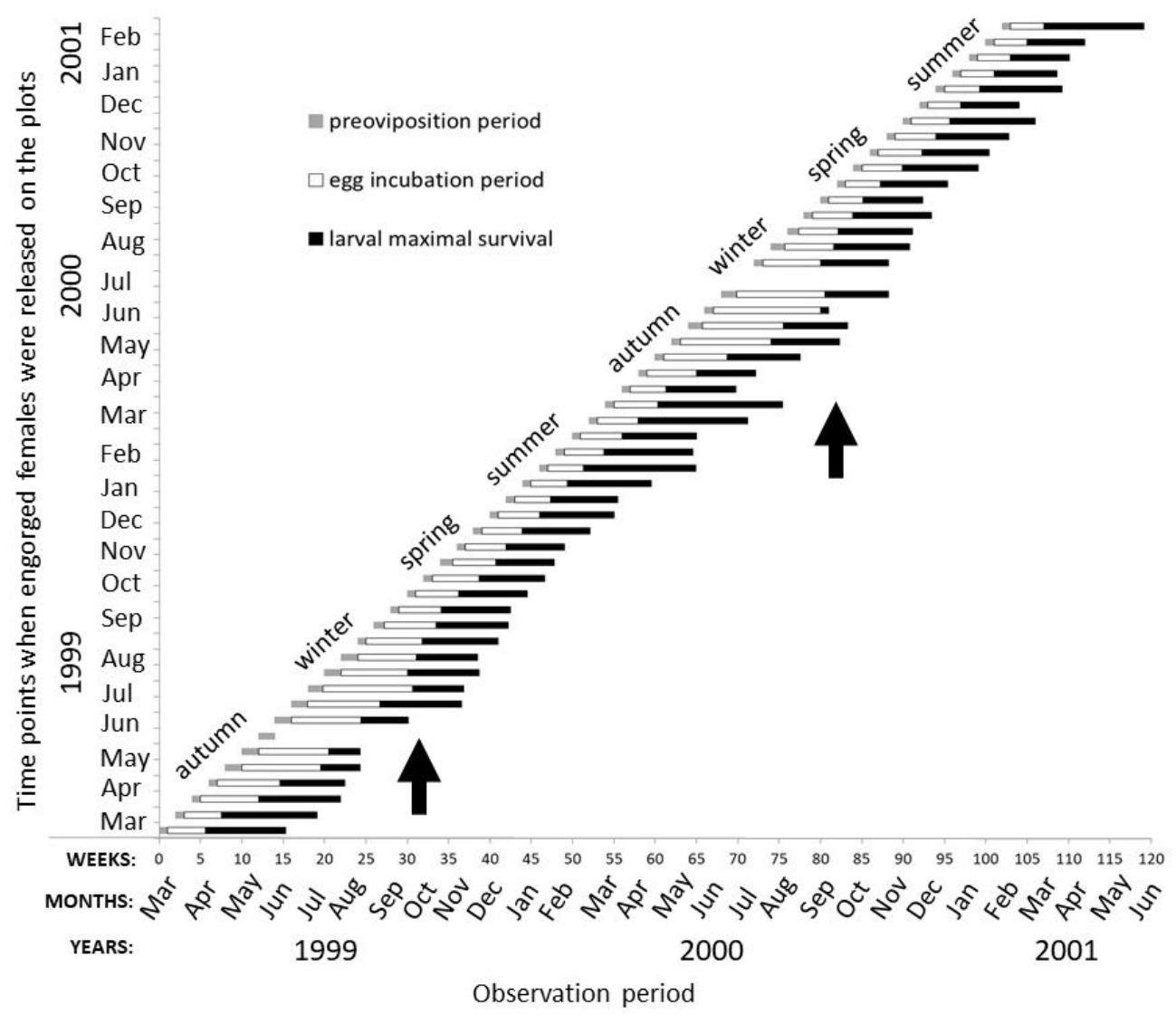

Figure 2. Dermacentor nitens reproductive and survival mean periods for females and larvae, respectively, observed in grass plots under field conditions. Groups of engorged females confined to cylindrical tubes were placed on the soil base under the vegetation of grass plots at 14-day intervals from March 1999 to February 2001. Black arrows indicate the spring synchronism of larval hatching in the plots where engorged females were released in the previous winter and late autumn. 

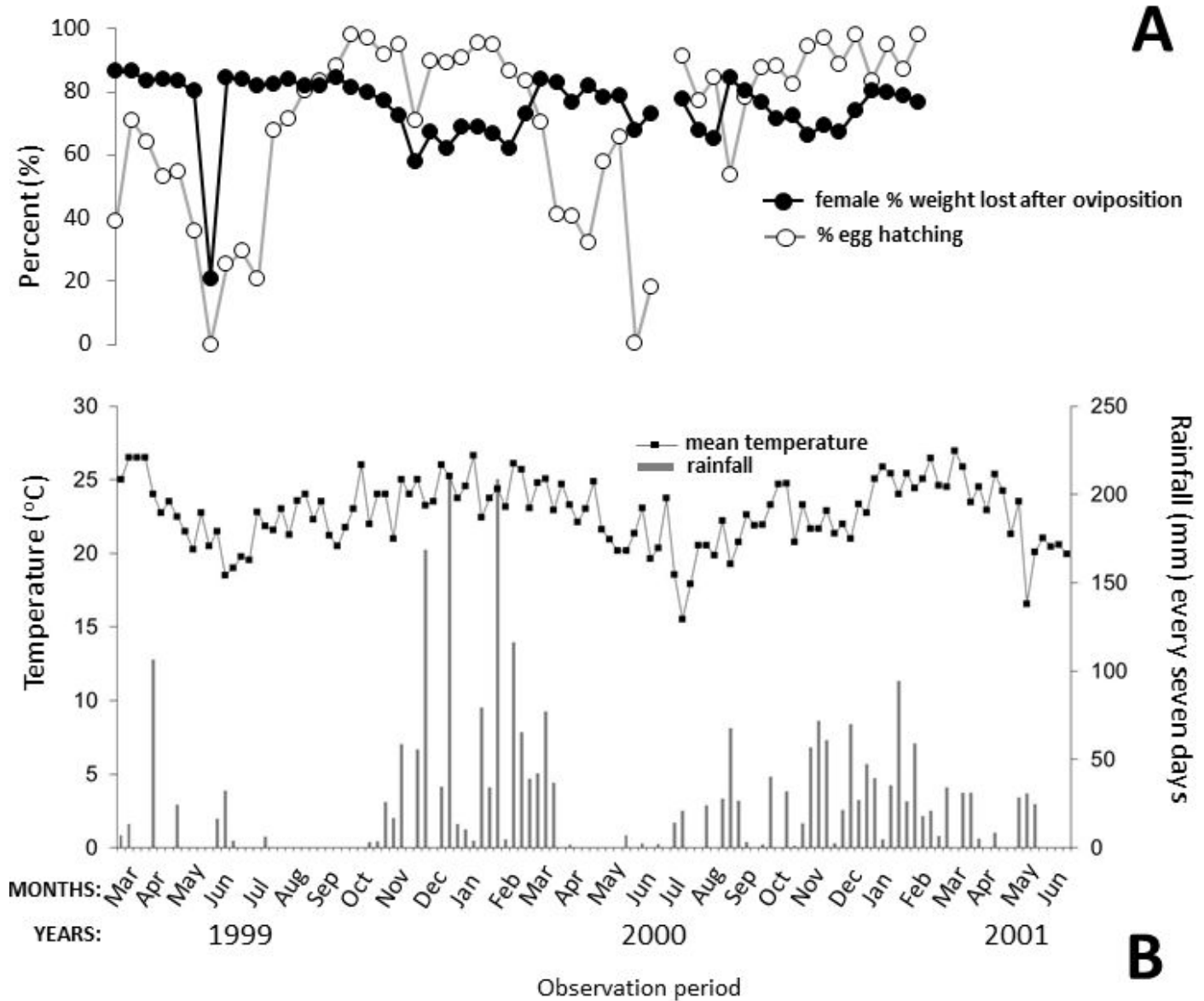

Figure 3. (A) Reproductive data of Dermacentor nitens observed in grass plots under field conditions. Groups of engorged females confined to cylindrical tubes were placed on the soil base under the vegetation of grass plots at 14-day intervals from March 1999 to February 2001; (B) Climatic data at seven-day intervals for the study period. Mean temperature was calculated based on the maximum and minimum soil temperatures of the previous seven days; rainfall data are presented as the sum (in millimeters) of the previous 7 days.

Table 2. Biological data for Dermacentor nitens engorged females confined to cylindrical tubes on grass plots at Pirassununga, São Paulo state, Brazil*.

\begin{tabular}{|c|c|c|c|c|c|}
\hline Months" & $\begin{array}{l}\text { Preoviposition } \\
\text { period (weeks) }\end{array}$ & $\begin{array}{c}\text { Egg mass } \\
\text { incubation period } \\
\text { (weeks) }{ }^{+}\end{array}$ & $\%$ Egg hatching ${ }^{+}$ & $\begin{array}{l}\text { Female \% weight lost } \\
\text { after oviposition }^{+}\end{array}$ & $\begin{array}{c}\text { Maximal larval } \\
\text { survival (weeks) }\end{array}$ \\
\hline March & $1.0 \pm 0.0(1-1) c$ & $4.9 \pm 0.1(3-7) d, e, f$ & $70.0 \pm 4.5(0-99) b$ & $78.4 \pm 2.1(5-95) a, b$ & $11.9 \pm 0.5$ (4-19)a \\
\hline April & $1.0 \pm 0.0(1-1) c$ & $6.2 \pm 0.2(4-9) c$ & $49.9 \pm 4.5(0-95) c$ & $81.8 \pm 1.3(44-95) a$ & $8.4 \pm 0.3(1-13) b$ \\
\hline May & $1.5 \pm 0.1(1-2) b$ & $9.2 \pm 0.2(7-12) b$ & $45.3 \pm 4.9(1-99) c, d$ & $80.9 \pm 0.9(60-93) a, b$ & $6.5 \pm 0.5(2-11) c$ \\
\hline June & $1.6 \pm 0.1(1-2) b$ & $9.3 \pm 0.3(7-13) a, b$ & $29.4 \pm 6.6(0-99) d, e$ & $62.9 \pm 4.2(14-86) d$ & $6.8 \pm 0.6(1-10) b, c$ \\
\hline July & $1.9 \pm 0.1(1-3) a$ & $10.0 \pm 0.3(7-13) a$ & $22.7 \pm 4.4(0-80) \mathrm{e}$ & $79.7 \pm 1.1(64-92) a, b$ & $7.9 \pm 0.5(4-13) b, c$ \\
\hline August & $1.7 \pm 0.1(1-2) a, b$ & $6.7 \pm 0.2(4-10) c$ & $76.0 \pm 5.0(0-99) a, b$ & $76.3 \pm 2.0(26-92) a, b$ & $8.5 \pm 0.3(2-11) b$ \\
\hline September & $1.0 \pm 0.0(1-2) c$ & $5.4 \pm 0.1(4-8) d$ & $76.6 \pm 4.1(1-99) a, b$ & $82.6 \pm 0.7(68-93) a$ & $8.6 \pm 0.3(1-12) b$ \\
\hline October & $1.0 \pm 0.0(1-1) c$ & $5.1 \pm 0.1(4-6) d, e$ & $92.9 \pm 2.8$ (15-99)a & $77.4 \pm 1.1(58-90) a, b$ & $8.4 \pm 0.2(5-11) b$ \\
\hline November & $1.1 \pm 0.1(1-2) c$ & $5.1 \pm 0.1(4-6) d, e$ & $90.9 \pm 2.1(50-99) a$ & $72.1 \pm 1.3(48-92) b, c, d$ & $7.8 \pm 0.3(5-12) b, c$ \\
\hline December & $1.0 \pm 0.0(1-1) c$ & $4.6 \pm 0.1(4-5) e, f, g$ & $86.4 \pm 4.1(0-99) a, b$ & $65.3 \pm 2.8(7-85) c, d$ & $8.8 \pm 0.3(6-13) b$ \\
\hline January & $1.0 \pm 0.0(1-1) c$ & $4.2 \pm 0.1(4-5) \mathrm{g}$ & $91.2 \pm 3.2(0-99) a$ & $72.9 \pm 1.8(5-94) b, c$ & $8.6 \pm 0.3(5-14) b$ \\
\hline February & $1.0 \pm 0.0(1-1) c$ & $4.3 \pm 0.1(4-5) f, g$ & $93.9 \pm 1.6(50-99) a$ & $72.6 \pm 1.3(43-90) b, c$ & $10.9 \pm 0.5(5-17) a$ \\
\hline
\end{tabular}

* The lots of engorged females were formed every 14 days from March 1999 to February 2001; data were pooled for all lots from the same month over the 24-month period; " refers to the month when the engorged females were released in the grass plots; ${ }^{+}$Values presented as the mean \pm standard error (range in parenthesis); different letters in the same column indicate significantly different mean values $(P<0.05)$. 
were released in February and March (mid to late summer) and significantly lower in plots where females were released in May to July (mid-autumn to early winter) and November (mid-spring).

\section{Ticks released freely in grass plots}

Ticks released freely in the grass plots were formed every 14 days, except for mid-July 2000, when the number of engorged females recovered from horses was not enough to form the groups. As illustrated in Figure 4, the duration of the prehatch period (number of weeks between placement of engorged females and first appearance of host seeking larvae on tip of grasses) was longer in the autumn and winter months and shorter in the spring and summer months. During the spring of both 1999 and 2000, there was a certain synchronism of the first appearance of host-seeking larvae on the tip of the grasses in the plots where the engorged females were released in the previous winter and late autumn. This spring synchronism coincided with an increase in both temperature and rainfall in the plots after an autumn and winter with lower temperatures and rainfall (Figure 3B). Generally, when the vast majority of the larvae had died in the plots, the few remaining live larvae $(<10)$ were observed for only a short additional period (mean: 1.1 week; range: 0 - 5 weeks). The longest periods of maximal larval survival were observed in the plots where engorged females were released in early autumn of both 1999 (14 weeks) and 2000 (13 weeks). The shortest periods of maximal larval survival (1 to 2 weeks) were observed in the plots where engorged females were released in the winter of 2000 and the summer of 2000/2001. For the first 12 months of the study (March 1999 to February 2000), the shortest periods of larval survival were observed in plots where engorged females were released in mid-summer ( 3 to 5 weeks).

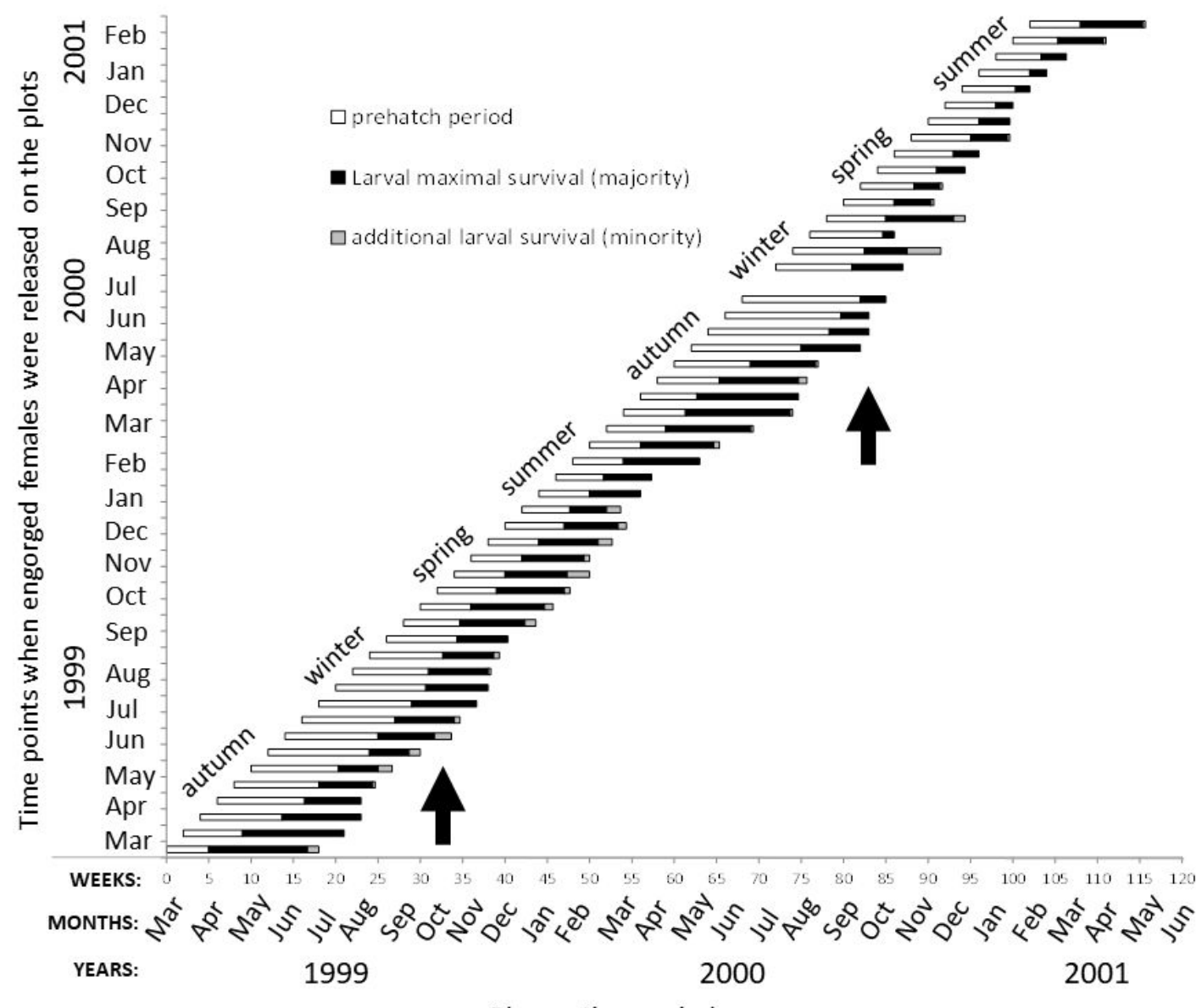

Observation period

Figure 4. Dermacentor nitens reproductive and survival mean periods for females and larvae, respectively, observed in grass plots under field conditions. Groups of engorged females were released freely on the soil base under the vegetation of grass plots at 14-day intervals from March 1999 to February 2001. Black arrows indicate the spring synchronism of the first appearance of hostseeking larvae on the tip of grasses in the plots where engorged females were released in the previous winter and late autumn. 
Through comparisons of the pooled data per month, the biological variables showed some marked differences among the 12 months of the year. The prehatch period was significantly longer for the females released in the field during the autumn and winter months (between late March and late September) when compared to the females released during the spring and summer months (between late September and late March) (Table 3). Larval survival was in most of the times significantly longer in the plots where females were released in March and April (late summer to early autumn).

Table 3. Biological data for Dermacentor nitens engorged females released freely on grass plots at Pirassununga, São Paulo state, Brazil*.

\begin{tabular}{|c|c|c|c|}
\hline \multirow{2}{*}{ Months" } & \multirow{2}{*}{ Prehatch period (weeks) ${ }^{+}$} & \multicolumn{2}{|c|}{ Survival of unfed larvae (weeks) } \\
\hline & & Majority $^{+}$ & Maximal + \\
\hline March & $6.5 \pm 0.2(5-8) f, g$ & $10.9 \pm 0.4(8-13) a$ & $11.5 \pm 0.5(9-14) a$ \\
\hline April & $8.5 \pm 0.5(6-11) d, e$ & $9.3 \pm 0.6(6-13) a, b$ & $9.6 \pm 0.6(6-13) a, b$ \\
\hline May & $10.6 \pm 0.4(9-13) b, c$ & $6.4 \pm 0.4(3-8) c$ & $7.0 \pm 0.4(5-9) b, c$ \\
\hline June & $12.8 \pm 0.4(11-15) a$ & $4.8 \pm 0.6(1-7) c, d$ & $5.7 \pm 0.7(3-11) c, d$ \\
\hline July & $12.0 \pm 0.5(10-14) a, b$ & $5.9 \pm 0.7(2-8) c, d$ & $6.1 \pm 0.8(2-9) b, c, d$ \\
\hline August & $9.3 \pm 0.3(8-11) c, d$ & $5.3 \pm 0.7(1-8) c, d$ & $6.0 \pm 0.8(1-9) c, d$ \\
\hline September & $7.3 \pm 0.3(6-9) e, f$ & $6.4 \pm 0.5(4-11) c$ & $7.1 \pm 0.5(4-11) b, c$ \\
\hline October & $6.6 \pm 0.1(6-7) f, g$ & $5.8 \pm 0.8(1-9) c, d$ & $6.3 \pm 0.9(2-11) b, c, d$ \\
\hline November & $6.5 \pm 0.1(6-7) f, g$ & $5.5 \pm 0.6(1-9) c, d$ & $6.4 \pm 0.9(1-11) b, c, d$ \\
\hline December & $6.3 \pm 0.1(6-7) f, g$ & $4.8 \pm 0.6(2-7) c, d$ & $5.4 \pm 0.9(2-12) c, d$ \\
\hline January & $5.9 \pm 0.1(5-7) g$ & $3.4 \pm 0.6(1-8) d$ & $3.7 \pm 0.7(1-8) d$ \\
\hline February & $5.8 \pm 0.1(5-6) g$ & $6.8 \pm 0.6(3-11) b, c$ & $7.0 \pm 0.6(4-11) b, c$ \\
\hline
\end{tabular}

* the lots of engorged females were formed every 14 days from March 1999 to February 2001; data were pooled for all lots from the same month over the 24-month period; " refers to the month when the engorged females were released in the grass plots; ${ }^{+}$Values presented as the mean \pm standard error (range in parenthesis); different letters in the same column indicate significantly different mean values $(P<0.05)$.

\section{Discussion}

By exposing engorged females of $D$. nitens to field conditions for 24 consecutive months, this tick species was able to complete its nonparasitic phase by producing host-seeking larvae in the pasture throughout the year. These results are consistent with those of previous studies that observed horses naturally infested by $D$. nitens throughout the year in southeastern Brazil (Souza \& Serra-Freire, 1992; Borges et al., 1999; Labruna et al., 2002). During the autumn and winter months of the present study, preoviposition and egg incubation periods were longer, certainly because of the lower mean temperature on soil during these seasons of the years. This statement is supported by laboratory studies that demonstrated an inverse effect of temperature, regardless of relative humidity, on the duration of preoviposition and egg incubation periods of D. nitens (Despins, 1992; Bastos et al., 1996; de la Vega \& Díaz, 2000).

Overall, the number of larvae generated by engorged females was in most of the times lower during the autumn and winter months than during the other months, as demonstrated by lower egg hatching values. Such conditions could be linked to the lower mean temperatures and to a possible low relative humidity at the soil base during these periods of the year, when rainfall was low. These statements are corroborated by laboratory studies with D. nitens, in which there was a marked decrease in egg hatching at lower relative humidity values (Despins, 1992) and at $18^{\circ} \mathrm{C}$ compared to 27 or $32^{\circ} \mathrm{C}$ (Bastos et al., 1996).

Larval survival was in most of the times significantly longer in plots where females were released during late summer to early autumn. In this case, larvae with the longest longevity values ( $\approx 11$ weeks) hatched from eggs with the shortest incubation periods (egg incubation periods $4-5$ weeks or prehatch periods $\approx 6$ weeks). This combination of short egg incubation or prehatch period and long larval longevity was previously observed for another population 
of $D$. nitens in the state of Minas Gerais (Borges et al., 1999) and for several populations of two other one-host ticks, Rhipicephalus microplus (Canestrini, 1888) in Brazil (Gonzales et al., 1985) and Argentina (Canevari et al., 2017; Nava et al., 2020) and Rhipicephalus australis Fuller, 1899 [formerly R. microplus (Estrada-Peña et al., 2012)] in Australia (Harley, 1966). On the other hand, significantly shorter larval survival periods were observed in plots where females were released during (i) late autumn to winter, and (ii) spring to early summer than during other periods. In the first case, the larval survival period was possibly negatively affected by the long period of stress to which overwintering eggs were subjected, as previously reported for R. microplus (Canevari et al., 2017; Nava et al., 2020). In the second case, the short larval survival period was possibly a result of higher mean temperatures, which killed larvae faster by desiccation or starvation; in the latter case, it was assumed that larvae tended to exhaust their energy reserves faster under higher temperatures, as previously reported for $R$. australis (Wilkinson \& Wilson, 1959) and R. microplus (Canevari et al., 2017).

Several field studies with $R$. australis-infested cattle in Australia documented the so-called "spring rise", which refers to the sudden increase in the numbers of $R$. australis larvae attaching to cattle during the spring when there is simultaneous hatching of eggs laid over a comparatively long period (during late autumn and winter) (Norris, 1957; Snowball, 1957). The phenomenon of "spring rise" has also been proposed to occur with $D$. nitens in Minas Gerais state, Southeastern Brazil (Borges et al., 1999). The present study demonstrated an apparent synchronism of larval hatching within cylindrical tubes or the first appearance of host-seeking larvae on the tips of grasses during the spring seasons of both 1999 and 2000. In fact, such synchronism can be interpreted as the basis for the so-called "spring rise", which might result in a sudden increase in the abundance of $D$. nitens infestation on horses during the spring season under the conditions of southeastern Brazil.

Labruna et al. (2002) evaluated the seasonal dynamics of $D$. nitens infestations on horses on the same farm as in the present study. In that study, ten horses naturally infested by $D$. nitens were stocked in a $D$. nitens-free pasture on September 1997, and tick counts (engorged females $>4 \mathrm{~mm}$ in length) on horses were performed at 14-day intervals from October 1997 to September 1999. Noteworthy, the temperature and rainfall regimens reported by Labruna et al. (2002) for the 1997-1999 periods were very similar to those observed in the present study. During the first year of the study of Labruna et al. (2002), tick counts on horses consisted of no engorged females during the first two months (October and November 1997) since the pasture was free of $D$. nitens before the study. Thereafter, infestations consisted of a first peak in December 1997, a second in February-March 1998, a third in April-May 1998, a fourth in July-August 1998, and a fifth in October-November 1998. The stocking rate dropped to half, and infestations remained relatively low during the entire second year, precluding peak distinctions (Labruna et al., 2002). The five distinct peaks of the first year suggest the completion of five tick generations in a one-year period, a condition corroborated by the nonparasitic data generated in the present study. In this case, it was assumed that the detached engorged females of the first peak (December 1997) might have yielded host-seeking larvae in the pasture 6.3 weeks later, according to the mean prehatch period for December (Table 3). Considering a parasitic phase of 3.7 weeks on horses for this D. nitens population (Labruna \& Amaku, 2006), the interval of the first (December) and second (February-March) peaks of engorged females on horses was supported by these numbers $[(6.3+3.7=10$ weeks (=70 days)]. The detached engorged females of the second peak (February-March 1998) might have yielded host-seeking larvae in the pasture 5.8-6.5 weeks later (Table 3), which added to a parasitic phase of 3.7 weeks, give an interval of 66-71 days between the second (February-March) and third (April-May) peaks of engorged females on horses. The detached engorged females of the third peak (April-May 1998) might have yielded host-seeking larvae in the pasture 8.5-10.6 weeks later (Table 3), which added to a parasitic phase of 3.7 weeks, gives an interval of 85-100 days between the third (April-May) and fourth (July-August) peaks of engorged females on horses. Finally, the detached engorged females of the fourth peak (July-August 1998) might have yielded host-seeking larvae in the pasture 9.3-12.0 weeks later (Table 3), which added to a parasitic phase of 3.7 weeks, giving an interval of 91110 days between the fourth (July-August) and fifth (October-November) peaks of engorged females on horses. This nearly 'perfect' congruence of periods supports the completion of five generations per year for $D$. nitens in Pirassununga municipality, São Paulo state, southeastern Brazil.

In the study of Labruna et al. (2002), the first four peaks of infestations (from December 1997 to July-August 1998) on horses were increasing, followed by a fifth peak (October-November 1998) lower than the fourth. Based on the nonparasitic phase data generated in the present study, it can be inferred that the increasing peaks of engorged females from late spring (December) to winter (July-August) were supported by high egg hatching values during summer and autumn, whereas the fifth peak was possibly affected by lower egg hatching values during winter. 
Finally, a recent study in Jaboticabal municipality, state of São Paulo (around $115 \mathrm{~km}$ far from our present study site, and at similar altitude), reported that the local average temperature has risen by 3.3 and $3.78^{\circ} \mathrm{C}$ over the last 20 and 30 years, respectively (Cruz et al., 2020). If such climate change has occurred in other areas, and affected the seasonal dynamics of $D$. nitens, it remains to be investigated.

\section{Conclusions}

The present evaluation of the nonparasitic phase of $D$. nitens under field conditions indicates that this tick can successfully produce viable offspring throughout the year, although the number of hatched larvae would be smaller during late winter due to lower egg hatching rates during winter. Although the preoviposition and egg incubation periods were longer during autumn-winter than spring-summer months, $D$. nitens would be able to complete up to five generations per year. The results of this study might be used as baseline data for producing rational methods of tick control on horses, such as strategic control based on acaricide treatments of horses or pasture-spelling protocols based on periods of larval longevity in pastures.

\section{Acknowledgements}

Thank you to João A. Metzner, Antonio Santa-Roza and José Roberto Devitto (University of São Paulo, Pirassununga Campus) for their great technical support during field work and to David Evans (Royal Society of Biology, London, UK) for his valuable participation in planning the present study. This study was financed in part by the Coordenação de Aperfeiçoamento de Pessoal de Nível Superior - Brasil (CAPES) - Finance Code 001 and Fundação de Amparo à Pesquisa do Estado de São Paulo (FAPESP 2013/18046-7).

\section{References}

Aragão HB, Fonseca F. Notas de Ixodologia. VII- Otocentor nitens (Neumann, 1897) versus Anocentor columbianus Schulze, 1937 e comentários sôbre a rápida disseminação desse ixodideo no Brasil (Acari: ixodidae). Mem Inst Oswaldo Cruz 1953; 51(0): 499501. http://dx.doi.org/10.1590/S0074-02761953000100016.

Bastos KMS, Daemon E, Faccini JLH, Cunha DW. Efeitos de diferentes temperaturas sobre a fase não parasitária de Dermacentor (Anocentor) nitens (Neumann, 1987) (Acari: Ixodidae) em condições de laboratório. Rev Bras Parasitol Vet 1996; 5(1): 29-32.

Borges LMF, Oliveira PR, Ribeiro MFB. Seasonal dynamics of Anocentor nitens on horses in Brazil. Vet Parasito/ 2000; 89(3): 165171. http://dx.doi.org/10.1016/S0304-4017(00)00204-1. PMid:10760407.

Borges LMF, Oliveira PR, Ribeiro MFB. Seasonal dynamics of the free-living phase of Anocentor nitens at Pedro Leopoldo, Minas Gerais, Brazil. Vet Parasitol 1999; 87(1): 73-81. http://dx.doi.org/10.1016/S0304-4017(99)00155-7. PMid:10628702.

Campos JBV, André MR, Gonçalves LR, Freschi CR, Santos FM, de Oliveira CE, et al. Assessment of equine piroplasmids in the Nhecolândia sub-region of Brazilian Pantanal wetland using serological, parasitological, molecular, and hematological approaches. Ticks Tick Borne Dis 2019; 10(3): 714-721. http://dx.doi.org/10.1016/j.ttbdis.2019.03.002. PMid:30876824.

Canevari JT, Mangold AJ, Guglielmone AA, Nava S. Population dynamics of the cattle tick Rhipicephalus (Boophilus) microplus in a subtropical subhumid region of Argentina for use in the design of control strategies. Med Vet Entomol 2017; 31(1): 6-14. http:// dx.doi.org/10.1111/mve.12199. PMid:27747901.

Cruz BC, de Lima Mendes AF, Maciel WG, dos Santos IB, Gomes LVC, Felippelli G, et al. Biological parameters for Rhipicephalus microplus in the field and laboratory and estimation of its annual number of generations in a tropical region. Parasitol Res 2020; 119(8): 2421-2430. http://dx.doi.org/10.1007/s00436-020-06758-5. PMid:32548738.

de Barros MNDL, Riet-Correa F, Azevedo SS, Labruna MB. Off-host development and survival of Rhipicephalus (Boophilus) microplus in the Brazilian semiarid. Vet Parasitol Reg Stud Rep 2017; 9: 17-24. http://dx.doi.org/10.1016/j.vprsr.2017.04.004. PMid:31014836.

de la Vega R, Díaz G. Thermal constant estimation in tropical horse tick, Anocentor nitens (Acari: Ixodidae). Ann N Y Acad Sci 2000; 916(1): 298-302. https://doi.org/10.1111/j.1749-6632.2000.tb05304.x.

Despins JL. Effects of temperature and humidity on ovipositional biology and egg development of the tropical horse tick, Dermacentor (Anocentor) nitens. J Med Entomol 1992; 29(2): 332-337. http://dx.doi.org/10.1093/jmedent/29.2.332. PMid:1495053.

Estrada-Peña A, Venzal AJ, Nava S, Mangold A, Guglielmone AA, Labruna MB, et al. Reinstatement of Rhipicephalus (Boophilus) australis (Acari: Ixodidae) with redescription of the adult and larval stages. J Med Entomol 2012; 49(4): 794-802. http://dx.doi. org/10.1603/ME11223. PMid:22897039. 
Falce HC, Flechtmann CHW, Fernandes BF. Ixodidae (Acari) on horses, mules and asses in the state of Paraná, Brazil. Rev Fac Med Vet Zootec Univ S Paulo 1983; 20(2): 103-106. http://dx.doi.org/10.11606/issn.2318-3659.v20i2p103-106.

Gonzales JC, da Silva NR, Franco N, Pereira IHO. A vida livre do Boophilus microplus (Can. 1887). Arq Fac Vet UFRGS $1985 ;$ 3(1): 21-28.

Guglielmone AA, Sánchez ME, Franco LG, Nava S, Rueda LM, Robbins RG. Names of species of hard ticks [online]. Rafaela: Instituto Nacional de Tecnologia Agropecuária; 2015 [cited 2020 July 19]. Available from: http://rafaela.inta.gob.ar/nombresgarrapatas/

Harley KLS. Studies on the survival of the non-parasitic stages of the cattle tick Boophilus microplus in three climatically dissimilar districts of north Queensland. Aust J Agric Res 1966; 17(3): 387-410. http://dx.doi.org/10.1071/AR9660387.

Kerber CE, Labruna MB, Ferreira F, De Waal DT, Knowles DP, Gennari SM. Prevalence of equine Piroplasmosis and its association with tick infestation in the State of São Paulo, Brazil. Rev Bras Parasito/ Vet 2009; 18(4): 1-8. http://dx.doi.org/10.4322/rbpv.01804001. PMid:20040201.

Labruna MB, Amaku M, Metzner JA, Pinter A, Ferreira F. Larval behavioral diapause regulates life cycle of Amblyomma cajennense (Acari: Ixodidae) in Southeast Brazil. J Med Entomol 2003; 40(2): 170-178. http://dx.doi.org/10.1603/0022-2585-40.2.170. PMid:12693845.

Labruna MB, Amaku M. Rhythm of engorgement and detachment of Anocentor nitens females feeding on horses. Vet Parasitol 2006; 137(3-4): 316-332. http://dx.doi.org/10.1016/j.vetpar.2006.01.025. PMid:16481114.

Labruna MB, Camargo LMA, Terrassini FA, Ferreira F, Schumaker TTS, Camargo EP. Ticks (Acari: Ixodidae) from the State of Rondônia, western Amazon, Brazil. Syst App/ Acarol 2005; 10(0): 17-32. http://dx.doi.org/10.11158/saa.10.1.4.

Labruna MB, Kasai N, Ferreira F, Faccini JLH, Gennari SM. Seasonal dynamics of ticks (Acari: Ixodidae) on horses in the state of São Paulo, Brazil. Vet Parasitol 2002; 105(1): 65-77. http://dx.doi.org/10.1016/S0304-4017(01)00649-5. PMid:11879967.

Labruna MB, Kerber CE, Ferreira F, Faccini JLH, De Waal DT, Gennari SM. Risk factors to tick infestations and their occurrence on horses in the State of São Paulo, Brazil. Vet Parasitol 2001; 97(1): 1-14. http://dx.doi.org/10.1016/S0304-4017(01)00387-9. PMid:11337122.

Lado P, Klompen H. Evolutionary history of New World ticks of the genus Dermacentor (Ixodida: Ixodidae), and the origin of D. variabilis. Biol J Linn Soc Lond 2019; 127(4): 863-875. http://dx.doi.org/10.1093/biolinnean/blz063.

Nava S, Rossner MV, Torrents J, Morel N, Martinez NC, Mangold AJ, et al. Management strategies to minimize the use of synthetic chemical acaricides in the control of the cattle tick Rhipicephalus (Boophilus) microplus (Canestrini, 1888) in an area highly favourable for its development in Argentina. Med Vet Entomol 2020; 34(3): 264-278. http://dx.doi.org/10.1111/mve.12432. PMid:32031286.

Nava S, Venzal JM, González-Acuña D, Martins TF, Guglielmone AA. Ticks of the southern cone of America: diagnosis, distribution and hosts with taxonomy, ecology and sanitary importance. London: Elsevier, Academic Press; 2017.

Norris KR. Strategic dipping for control of the cattle tick, Boophilus microplus (Canestrini), in South Queensland. Aust J Agric Res 1957; 8(6): 768-787. http://dx.doi.org/10.1071/AR9570768.

Peckle M, Pires MS, Dos Santos TM, Roier EC, da Silva CB, Vilela JA, et al. Molecular epidemiology of Theileria equi in horses and their association with possible tick vectors in the state of Rio de Janeiro, Brazil. Parasitol Res 2013; 112(5): 2017-2025. http:// dx.doi.org/10.1007/s00436-013-3360-0. PMid:23474658.

Snowball GJ. Ecological observations on the cattle tick, Boophilus microplus (Canestrini). Aust J Agric Res 1957; 8(4): 394-413. http:// dx.doi.org/10.1071/AR9570394.

Souza AP, Serra-Freire NM. Variação sazonal dos estádios adultos de Amblyomma cajennense e Anocentor nitens, como parasitas de cavalos no município de Itaguaí, RJ, Brasil. Rev Bras Parasitol Vet 1992; 1(1): 31-34.

Souza EAR, Araujo AC, Pires LCSR, Freschi CR, Azevedo SS, Machado RZ, et al. Serological detection and risk factors for equine piroplasmosis in the semiarid region of Pernambuco, Northeastern Brazil. Rev Bras Parasitol Vet 2019; 28(4): 685-691. http:// dx.doi.org/10.1590/s1984-29612019088. PMid:31691736.

Sutherst RW, Wharton RH, Utech KBW. Guide to studies on tick ecology. Indooroopilly: CSIRO Division of Entomology; 1978.

Szabó MPJ, Martins MM, de Castro MB, Pacheco RC, Tolesano-Pascoli GV, dos Santos KT, et al. Ticks (Acari: Ixodidae) in the Serra da Canastra National Park in Minas Gerais, Brazil: species, abundance, ecological and seasonal aspects with notes on rickettsial infection. Exp App/ Acaro/ 2018; 76(3): 381-397. http://dx.doi.org/10.1007/s10493-018-0300-9. PMid:30317459.

Wilkinson PR, Wilson JT. Survival of cattle ticks in central Queensland pastures. Aust J Agric Res 1959; 10(1): 129-143. http://dx.doi. org/10.1071/AR9590129. 